\title{
Correction to: Mitochondrial Morphofunction in Mammalian Cells by Bulthuis EP et al. Antioxid. Redox Signal. 30: 2066-2109, 2019. DOI: 10.1089/ars.2018.7534.correx
}

N THE June 20, 2019 issue of Antioxidants \& Redox Signaling (vol. 30, no. 18; 2066-2109) the article entitled

"Mitochondrial Morphofunction in Mammalian Cells" by Bulthuis et al. requires correction.

Figure 1 contained an arrow pointing from right to left through the CII symbol, erroneously depicting CII as proton-pumping. The original Figure 1 is shown below:

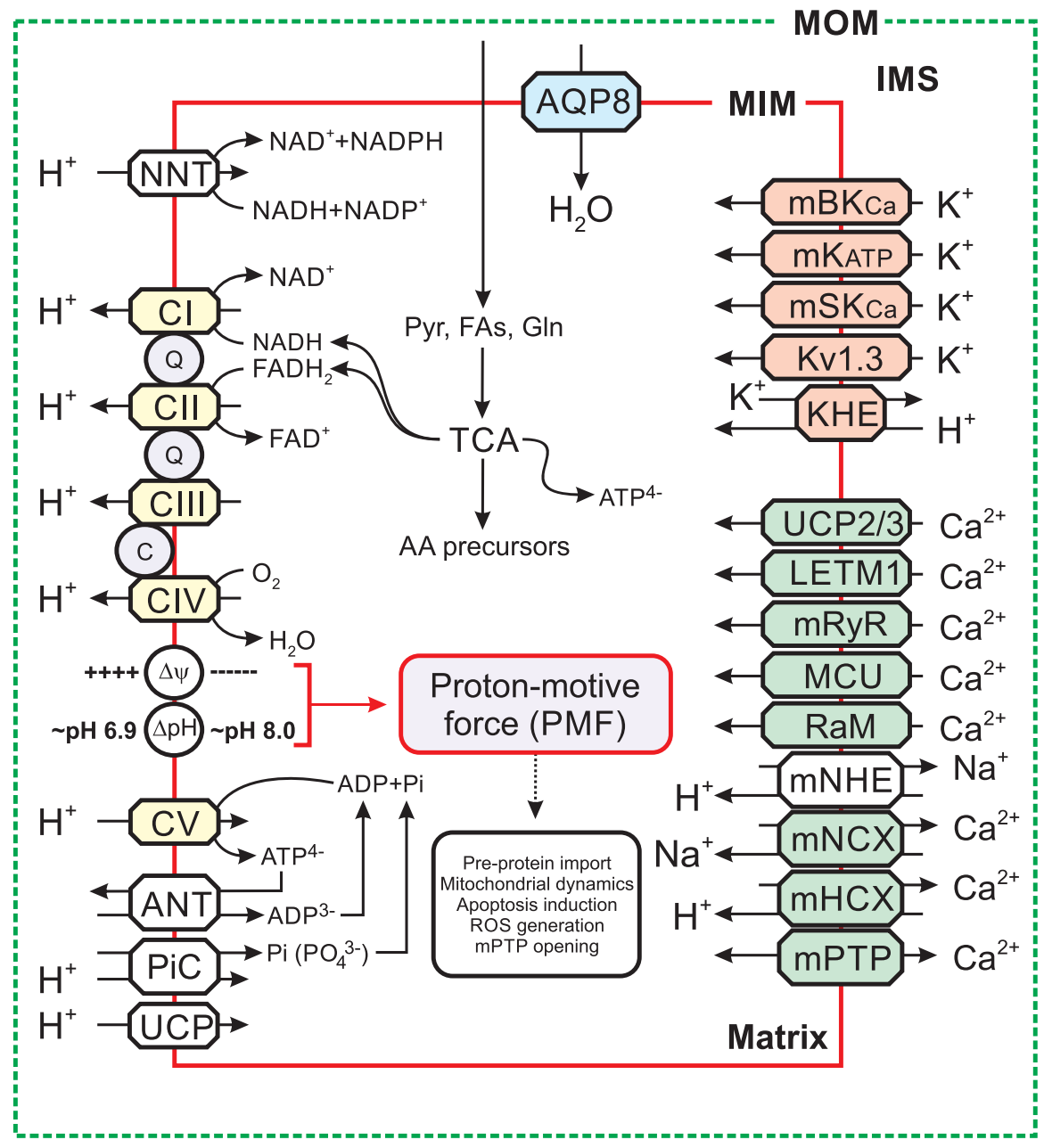


Figure 1 has been replaced with the correct image with the arrow removed:

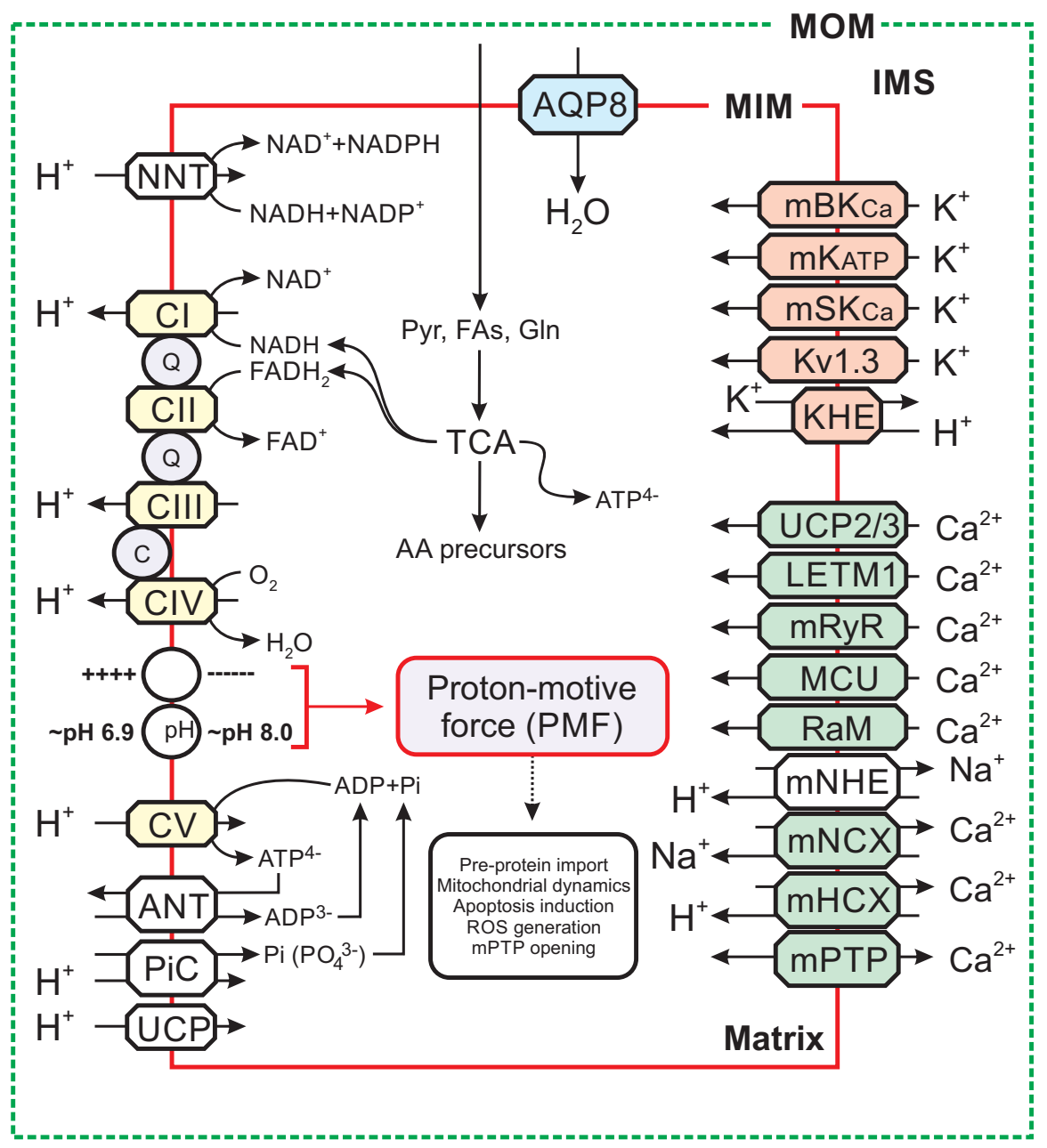

OXPHOS system

$\mathrm{K}^{+}$influx/efflux

$\mathrm{Ca}^{2+}$ influx/efflux

The online version has been corrected to reflect this. The authors apologize for this error. 